\title{
The effect of Er:YAG laser and different surface conditioning procedures on microtensile bond strength of the fissure sealant containing amorphous calcium phosphate after artificial aging
}

\author{
Murat UNAL ${ }^{1}$, Ihsan HUBBEZOGLU², Recai ZAN³ and Fatih OZNURHAN¹ \\ ${ }^{1}$ Department of Pedodontics, Faculty of Dentistry, Cumhuriyet University, Sivas, Turkey \\ ${ }^{2}$ Department of Restorative Dentistry, Faculty of Dentistry, Cumhuriyet University, Sivas, Turkey \\ ${ }^{3}$ Department of Endodontics, Faculty of Dentistry, Cumhuriyet University, Sivas, Turkey \\ Corresponding author, Murat UNAL; E-mail: gmuratunal@hotmail.com
}

\begin{abstract}
The present study aimed to compare post-aging microtensile values of fissure sealant(FS) containing amorphous calcium phosphate(ACP) with or without bonding after various enamel-etching methods. The buccal enamel surfaces of teeth were prepared and divided into five main groups according to enamel etching (Group 1; acid-etching, Group 2; air-abrasion, Group 3; 2W, Group 4; 3W, and Group 5; 4W of Er:YAG laser). Each main group was subdivided as with(Subgroup B) or without(Subgroup A) a bonding system. We applied FS-containing ACP to etched enamel surfaces. All specimens were aged by Thermocycling and water bath. We then measured microtensile bond strengths and analyzed data with two-way ANOVA and Tukey's tests. We found a statistically significant difference between Group 1 and Group 2, between Subgroup B of Group 5 and Subgroups B of all other groups, and between Subgroups A and Subgroups B of all main groups $(p<0.01)$. Er:YAG laser-etching may be an alternative enamel etching method to acid-etching for ACP-containing FS.
\end{abstract}

Keywords: Fissure sealant, Er:YAG laser, Amorphous calcium phosphate, Aging

\section{INTRODUCTION}

In pediatric dentistry, dental caries is disease affecting the oral cavity at the occlusal pits and fissures. Complex morphology of occlusal surfaces that cause bacterial aggregation and proliferation is responsible for 60 $85 \%$ of carious lesions in these areas ${ }^{1}$. Pit and fissure sealants (PFSs) are conservative, painless, and often effective method for preventing occlusal caries ${ }^{2,3)}$. PFSs emerged in Buonocore's first studies of etching enamel in 1955). One develops PFSs by providing marginal integrity and enhancing retention by infiltrating resinbased materials into the enamel, etching in micro-spaces with phosphoric $\operatorname{acid}^{1}$. In pediatric dental treatments, PFSs are among the most effective materials for oral hygiene training, optimal fluoride intake, healthy diet habits and the prevention of pit and fissure caries ${ }^{1-3)}$.

Newly commercialized Aegis PFSs can release calcium and phosphate due to the presence of amorphous calcium phosphate (ACP). The sealant leaches hydroxyapatite (HAP) from the enamel surface, during a caries formation at or below $\mathrm{pH} 5.8^{5}$. At this low $\mathrm{pH}$ value, the ACP can break down and saturate the tooth with $\mathrm{Ca}^{2+}$ and $\mathrm{PO}_{4}$ ions ${ }^{6)}$. These concentrations help form HAP, which the tooth uses to remineralize its enamel ${ }^{7}$. The ACP not only indicates HAP, but exhibits anti-cariogenic properties and potential remineralization ${ }^{8)}$. We preferred Aegis PFS because of inadequate literature about microtensile bond strength on permanent teeth.

The success rate of the PFS depends on its retention on the tooth surface. A number of enamel preparation methods, such as air abrasion, enameloplasty, acid etching, and laser etching, ensure a more retentive tooth surface. Most widely used is application of $30-40 \%$ phosphoric acid. The phosphoric acid forms retentive enamel micro-porosities through decalcification and increases wettability and surface areas ${ }^{9}$. The process of etching forms a porous enamel layer where resin can flow. Porosity not only provides a broad surface area where resin can adhere, but establishes a ground for perfect mechanical retention ${ }^{10)}$.

Air-abrasion technology (kinetic cavity preparation) is another method suggested for etching the enamel surfaces ${ }^{11,12)}$. Air pressure is used to propel the $\mathrm{Al}_{2} \mathrm{O}_{3}$ particles and abrade the tooth surface. The advantages of preparing the enamel surface by removing superficial caries and dental plaque from the tooth surface are well known. $\mathrm{Al}_{2} \mathrm{O}_{3}$ powder could be applied on enamel surfaces with different particle sizes $(27,30$, and $50 \mu \mathrm{m})$ : we used $27 \mu \mathrm{m}$.

Laser etching in pediatric dentistry can be an alternative to acid etching. Hard tissue studies began when the FDA approved Er:YAG lasers on enamel and dentin in 1997. The Er:YAG laser, a pulsatile beam of $2.94 \mu \mathrm{m}$ wavelength, has various advantages on hard tissues. The water in dental hard tissue absorbs its energy ${ }^{13)}$. Moreover, the water-cooled system does not harm tooth pulp.

The use of bonding agents prior to PFS application increases bonding to dental tissue, decreases microleakage, obtains the flow of the resin material into pits and fissures and increases clinical success ${ }^{14-16)}$. This technique minimized salivary contamination of etched surfaces. Both laboratory studies and clinical study demonstrated it increased bond strength on the surface 
and effectively decreased microleakage. In the present research, we use an acetone-based and etch-and-rinse bonding agent (Prime \& Bond NT) ${ }^{17,19}$.

The purpose of the present study is to evaluate and compare post-aging microtensile values of fissure sealant (FS) containing ACP, with or without bonding after various enamel-etching methods (phosphoric acid, air abrasion, laser $2 \mathrm{~W}$, laser $3 \mathrm{~W}$, and laser $4 \mathrm{~W}$ ).

\section{MATERIALS AND METHODS}

This study used fifty human permanent mandibular molar teeth, caries-free, non-restored and without other microscopic defects. We polished them with pumice to remove any surface debris or contaminants and kept them in $0.1 \%$ thymol solution at room temperature before the experiment. Their roots were cut $2 \mathrm{~mm}$ below the cemento-enamel junction. Then, we embedded half the teeth's bucco-lingual distance horizontally into acrylic resins. We polished buccal enamel surface for 60 s under water cooling with 600-grit silicon carbide (SiC) paper to obtain a smooth, homogenous, and standard enamel surface.

The study tested one commercial acid etching (phosphoric acid), one air-abrasion system [aluminium oxide $\left(\mathrm{Al}_{2} \mathrm{O}_{3}\right)$ ], and three different Er:YAG laser (Smart 2940D Plus; DEKA Laser, Firenze, Italy) irradiation power energies.

We sorted specimens randomly into five groups ( $n=10$ teeth) according to enamel-etching methods:

Phosphoric acid group (Group 1): We used 35\% phosphoric acid gel (Bosworth Acid Etch, Bosworth Co, Illusiana, USA) to etch the teeth's buccal enamel surfaces for $30 \mathrm{~s}$, rinsed them thoroughly for $20 \mathrm{~s}$ and dried them using a mild, oil-free air spray for $10 \mathrm{~s}$ to get a uniform chalky-white appearance.

Air abrasion group (Group 2): The buccal enamel surfaces of the teeth were etched with air abrasion (Rondoflex-plus $360 \mathrm{Kavo}^{\circledR}$, Germany) at 80 psi with 27 micrometer aluminium oxide $\left(\mathrm{Al}_{2} \mathrm{O}_{3}\right)$ particles and in 2 $\mathrm{mm}$ distance from the specimen's surface for $30 \mathrm{~s}$. Thirty seconds of thorough water spray rinse removed residual aluminium particles.

Laser 2W (Group 3): An Er:YAG laser pulsed infrared radiation at a wavelength of $2,940 \mathrm{~nm}$ through an articulated arm. At the end of the articulated arm on the Smart2940 D system is a handpiece used in the non-contact (window) tip. Additionally, with the laser beam in focus at $1 \mathrm{~mm}$ from the window of the handpiece, presents a much smaller spot size than $1 \mathrm{~mm}$, due to its proximity. The laser was used with a handpiece head positioned $1 \mathrm{~mm}$ above and perpendicular to the enamel surface. 2W power energy of Er:YAG laser was applied on buccal enamel surfaces for enameletching. A pulse energy of $100 \mathrm{~mJ}$, a repetition rate of $20 \mathrm{~Hz}$, a pulse length of $230 \mu \mathrm{s}$ and sweeping fashion with a water flow of $5 \mathrm{~mL} / \mathrm{min}$ were the parameters of the laser for $30 \mathrm{~s}$.

Laser 3W (Group 4): 3W power energy of Er:YAG laser was applied on buccal enamel surfaces for enamel- etching. A pulse energy of $150 \mathrm{~mJ}$, a repetition rate of $20 \mathrm{~Hz}$, a pulse length $230 \mu \mathrm{s}$ and sweeping fashion with a water flow of $5 \mathrm{~mL} / \mathrm{min}$ were the parameters of the laser for $30 \mathrm{~s}$.

Laser 4W (Group 5): 4W power energy of Er:YAG laser was applied on buccal enamel surfaces for enameletching. A pulse energy of $200 \mathrm{~mJ}$, a repetition rate of $20 \mathrm{~Hz}$, a pulse length $230 \mu \mathrm{s}$ and sweeping fashion with a water flow of $5 \mathrm{~mL} / \mathrm{min}$ were the parameters of the laser for $30 \mathrm{~s}$.

After these procedures, we placed cylindrical transparent gelatins (diameter $4 \mathrm{~mm}$, height $8 \mathrm{~mm}$ ) on etched enamel surfaces. Then we divided each main group into two subgroups: A, to which we only applied fissure sealant, and B, to which we also applied a bonding agent, Prime \& Bond ${ }^{\circledR}$ NT (Dentsply Detrey, Konstanz, Germany).

Subgroup A: We applied Aegis fissure sealant (each 2-mm layer polymerized with Bluephase, with light intensity $1,200 \mathrm{mV} / \mathrm{cm}^{2}$, for $20 \mathrm{~s}$ ) on these teeth, in accordance with the instructions of the producing company (Table 1).

Subgroup B: We applied Prime \& Bond, again in accordance with the instructions of the producing company, and then Aegis fissure sealant (Table 1).

Then we built up approximately $4-\mathrm{mm}$ universal hybrid composite resins (Filtek ${ }^{\mathrm{TM}} \mathrm{Z250}$, colour A2, 3M ESPE) on the fissure sealant to obtain an adhesion surface for microtensile tests.

\section{Thermocycling and water-aging procedures}

Just after curing, we kept teeth in distilled water for $24 \mathrm{~h}$ and thermocycled them 10,000 times at $5-55^{\circ} \mathrm{C}$ in water baths for one min each. Following the thermocycling, the teeth were kept in the water bath at $37^{\circ} \mathrm{C}$ (Nüve BM 402, Ankara, Turkey) for 12 months.

After aging procedures, we kept samples in $37^{\circ} \mathrm{C}$ distilled water for $24 \mathrm{~h}$, and divided into rectangular prism-shaped sections measuring $1 \mathrm{~mm} \times 1 \mathrm{~mm}$, using a water-cooling cutting device (Isomet Buhler Ltd, Lake Bluff, IL, USA). A microtensile bond strength ( $\mu \mathrm{TBS}$ ) test was applied on 200 chosen sticks, including 20 from each group $(n=20)$.

We then fixed the sticks to the universal testing machine with cyonoacrylate and an accelerator (Zapit, Dental Ventures of America, Corona, CA, USA). In a universal test device (Lloyd LF Plus; Amatek Inc, Lloyd Instruments, Leicester, UK) $\mu \mathrm{TBS}$ applied $1 \mathrm{~mm}$ of power per min until failure occurred. We recorded the loading amount in the failure moment as megapascal $(\mathrm{MPa})$ and assessed results statistically.

A stereomicroscope at X40 (SZ-PT Olympus, Japan) helped identify slabs' fracture mode as either cohesive (within enamel or sealant), adhesive (between sealant and the enamel), or mixed (cohesive and adhesive fracture). A single observer (MÜ) blinded to the groups performed all analyses.

Scanning electron microscope analysis

One stick obtained from each group (adhesive, cohesive, 
Table 1 Materials used in the study

\begin{tabular}{|c|c|c|c|}
\hline Materials & Composition & Application procedures & LotNumber \\
\hline $\begin{array}{l}\text { AEGİS } \\
\text { Bosworth }{ }^{\circledR} \text { Company } \\
\text { (USA) }\end{array}$ & $\begin{array}{l}\text { UDMA, mono-and di } \\
\text { methacrylates resins } \\
\text { TLV-TWA: } 15 \mathrm{mg} / \mathrm{m}^{3} \mathrm{TWA} \\
\text { for ACP N/A for resin }\end{array}$ & $\begin{array}{l}\text { 1. After etching of enamel } \\
\text { 2. Apply sealant } \\
\text { 3. Wait for approximately } 15 \mathrm{~s} \\
\text { 4. Light-cure (Bluephase, İvoclar Vivadent, } \\
\text { Liechtenstein) for } 20 \mathrm{~s}\end{array}$ & 0608-398 \\
\hline $\begin{array}{l}\text { Prime\& Bond NT } \\
\text { (Dentsply DeTrey, } \\
\text { Germany) }\end{array}$ & $\begin{array}{l}\text { PENTA, UDMA, Resin R5-62-1, } \\
\text { T-resin, D-resin, nanofiller, } \\
\text { cetylaminehydrofluoride and acetone. }\end{array}$ & $\begin{array}{l}\text { 1. Apply adhesive under pressure for } 20 \mathrm{~s} \\
\text { 2. Dry with a gentle air stream for } 10 \mathrm{~s} \\
\text { 3. Light-cure (Bluephase, İvoclar Vivadent, } \\
\text { Liechtenstein ) for } 10 \mathrm{~s}\end{array}$ & 0703000381 \\
\hline
\end{tabular}

Bluephase, İvoclar Vivadent, Liechtenstein; light intensity: 1,200 $\mathrm{mW} / \mathrm{cm}^{2}$.

Abbreviations: Bis-GMA=bisphenol-A-glycidyl methacrylate; N/A=Not available; TEGDMA=triethyleneglycol dimethacrylate; TLV-TWA=Threshold Limit Value-Time-Weighted Average; UDMA=urethane dimethacrylate.
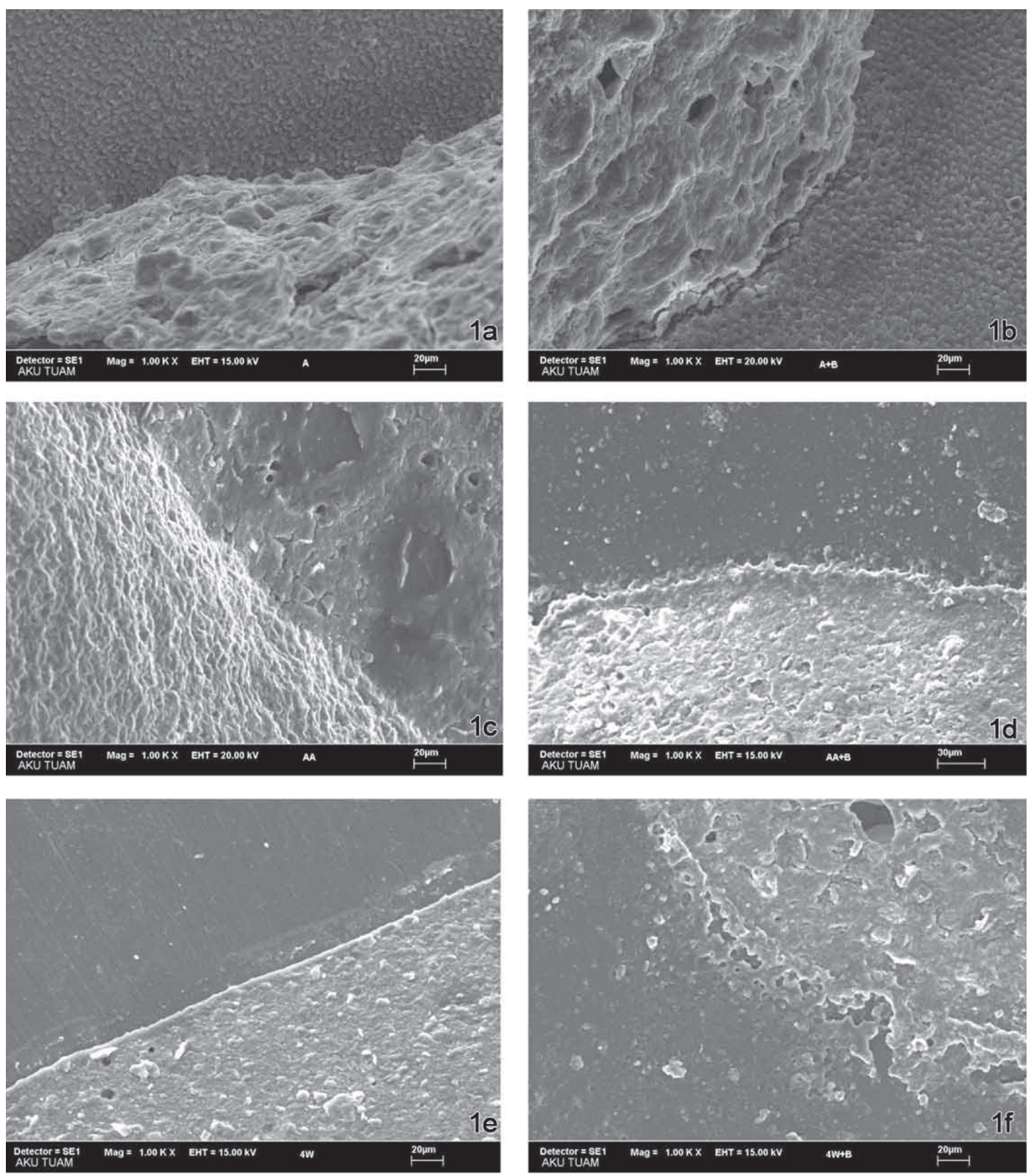

Fig. 1 SEM images of fracture [1a: Group 1(Subgroup A), 1b: Group 1 (Subgroup B), 1c: Group 2 (Subgroup A), 1d: Group 2 (Subgroup B), 1e: Group 5 (Subgroup A), 1f: Group 1 (Subgroup B)] 
and mixed) was separated for analysis after exposure to the microtensile process. A detailed imaging process in these samples probed the superficial changes on the joining area of enamel and fissure sealant. A sputter coater (SCD 005; Bal-Tec, Balzers, Liechtenstein), coated the specimens with a thin layer of gold, and the scanning electron microscope (SEM) (LEO 1430 VP, Carl Zeiss, Cambridge, England) evaluated and photographed the results to determine morphological differences between enamel and fissure sealant surface. The samples were examined at $1,000 \times$ magnification (Fig. 1). In the present study, Fig. 1 shows cohesive failure in Groups 1, 2 , and 5 (Subgroups A and B).

\section{Statistical analysis}

$\mu$ TBS values were calculated ( $\mathrm{MPa}$ ) and analyzed using two-way ANOVA. Multiple comparisons were performed using Tukey's test, with a significance level of 0.05. SPSS for Windows, Version 14.0 (SPSS Inc, Chicago,IL,USA) helped conduct statistical analysis.

\section{RESULTS}

Table 2 illustrates the statistical assessment of data.

In Subgroup A; there were statistical significant differences between Group 1 and Group $2(p<0.01)$. Furthermore, the statistical significant differences were found between Group 5 and Group 2, and $3(p<0.01)$.

In Subgroup B; there was the statistical significant difference between Group 1 and Group $2 \quad(p<0.01)$. Moreover, the statistical significant differences were found between Group 5 and the all other groups $(p<0.01)$.

There were statistically significant differences between Subgroups A and B in all main groups $(p<0.01)$.

Table 3 illustrates types of fracture. Recorded fractures were mainly cohesive (55-95\%) in all experimental groups.

Stereomicroscopic images obtained from sticks from Groups 1, 2, and 5 by universal test device are shown in Fig. 1. We indicated cohesive failure, the most common failure type.

The SEM image of Group 1 (Fig. 1a) without bonding agent showed a honeycomb-like appearance on the surface following organic debris cleaning. The SEM image of Group 2 (Fig. 1c) without bonding agent exhibited unevenness and irregularity of the enamel surface. The SEM image of Group 5 (Fig. 1e) without bonding agent showed the surface of the enamel almost entirely covered with fissure sealant.

The SEM image of Group 1 (Fig. 1b) with the bonding agent showed a honeycomb-like appearance on the surface, but intervals caused by bonding at the

Table 2 Mean and standard deviations of the microtensile bond strenght for each group

\begin{tabular}{lccccc}
\hline & \multicolumn{4}{c}{ Surface Pretreatment Procedure } \\
\cline { 2 - 6 } & $\begin{array}{c}\text { Group 1 } \\
\text { (Acid etching) }\end{array}$ & $\begin{array}{c}\text { Group 2 } \\
\text { (Air Abrasion) }\end{array}$ & $\begin{array}{c}\text { Group 3 } \\
(\text { Laser 2W) }\end{array}$ & $\begin{array}{c}\text { Group 4 } \\
(\text { Laser 3W) }\end{array}$ & $\begin{array}{c}\text { Group 5 } \\
(\text { Laser 4W) }\end{array}$ \\
\hline Aegis (SA) & $17.91(3.08)^{\mathrm{A}, \mathrm{a}}$ & $13.87(3.55)^{\mathrm{B}, \mathrm{a}, \mathrm{b}}$ & $15.64(3.20)^{\mathrm{C}, \mathrm{c}}$ & $17.06(3.39)^{\mathrm{D}}$ & $20.29(2.83)^{\mathrm{E}, \mathrm{b}, \mathrm{c}}$ \\
Bond+Aegis(SB) & $23.55(2.51)^{\mathrm{A}, \mathrm{d}, \mathrm{e}}$ & $19.14(2.85)^{\mathrm{B}, \mathrm{d}, \mathrm{f}}$ & $19.73(2.77)^{\mathrm{C}, \mathrm{g}}$ & $22.40(3.06)^{\mathrm{D}, \mathrm{h}}$ & $32.12(2.05)^{\mathrm{E}, \mathrm{e}, \mathrm{f}, \mathrm{g}, \mathrm{h}}$ \\
\hline
\end{tabular}

$n=20$ specimens per experimental condition.

Standard deviations are shown in parentheses.

By the two-way ANOVA: $F=246.412 P=0.000, p<0.01$ Tukey's test indicates statistical difference $(p<0.01)$ for means followed by the same letters; capital letters in the column are for the comparison of subgroup A and subgroup B with the same surface pretreatment; small letters in the rows are for the comparison of different surface pretreatment with the same subgroup.

Table 3 Fracture types of each group

\begin{tabular}{|c|c|c|c|c|c|c|c|c|c|c|}
\hline & \multicolumn{10}{|c|}{ Surface Pretreatment Procedure } \\
\hline & \multicolumn{2}{|c|}{$\begin{array}{c}\text { Group } 1 \\
\text { Acid etching }\end{array}$} & \multicolumn{2}{|c|}{$\begin{array}{c}\text { Group } 2 \\
\text { Air Abrasion }\end{array}$} & \multicolumn{2}{|c|}{$\begin{array}{c}\text { Group } 3 \\
\text { Laser } 2 \mathrm{~W}\end{array}$} & \multicolumn{2}{|c|}{$\begin{array}{c}\text { Group } 4 \\
\text { Laser 3W }\end{array}$} & \multicolumn{2}{|c|}{$\begin{array}{c}\text { Group } 5 \\
\text { Laser 4W }\end{array}$} \\
\hline & SA & SB & $\mathrm{SA}$ & SB & $\mathrm{SA}$ & SB & $\mathrm{SA}$ & SB & $\mathrm{SA}$ & SB \\
\hline Adhesive & 3 & 0 & 8 & 7 & 1 & 1 & 2 & 0 & 1 & 0 \\
\hline Cohesive & 16 & 17 & 10 & 12 & 19 & 17 & 14 & 19 & 18 & 20 \\
\hline Mix & 1 & 3 & 2 & 1 & 0 & 2 & 4 & 1 & 1 & 0 \\
\hline
\end{tabular}

$n=20$ specimens per experimental condition.

(SA: Subgroup A, SB: Subgroup B) 
enamel-sealant junction. The SEM image of Group 2 (Fig. 1d) with the bonding agent showed chalky surfaces and irregular porosity. The SEM image of Group 5 (Fig. 1f) with the bonding agent showed complete penetration of the enamel surface fissure sealant.

\section{DISCUSSION}

Conventional tensile and shear tests have evaluated the bond strength of fissure sealants to the enamel. Many current researchers prefer the microtensile technique, accepted as a more accurate method for evaluating bond strength ${ }^{20,21}$.

During clinical trials, in-vivo assessment of materials presented challenges. To imitate the natural aging process, in-vitro assessment was more favorable to simulations of oral cavity conditions (thermocycling, water aging, and chewing forces) in the laboratory environment. In microtensile tests conducted with fissure sealants, aging was ignored and omitted in almost all of the studies. Yet we know resin-containing materials might be affected by thermal changes in the oral environment, affecting test results obtained. This study differs from other microtensile bond strength studies in that all specimens were aged using thermocycling $\left(10,000\right.$ times) and water bath (at $37^{\circ} \mathrm{C}$ for 12 months).

The preventive success of fissure sealants depends on such factors as enamel surface properties, duration of acid-etching, type of acid and surface pre-treatment techniques. But the more important factor is fissure sealant retention, which depends on micro-mechanical and physico-chemical interactions between the resin and the etched enamel. Conventional acid etching has some disadvantages such as technical sensitivity, isolation problems and excessive time consumption. Researchers have thus sought alternative etching methods.

One such method is air abrasion. This nontraumatic method prevents heat and vibration that may otherwise cause microfractures. Knobloch et al. ${ }^{22}$ investigated the effect of different surface preparation techniques (air abrasion, etching with 37\% phosphoric acid, and a combination of both) on the bond strength of the resin-based fissure sealant. They found combined air-abrasion and acid-etching improved the bonding strength of the resin-based fissure sealant.

Moslemi et al. ${ }^{23)}$ reported that pre-treatment of the enamel surface with air-abrasion increased the bond strength of the fissure sealant; however, pretreatment with the_Er,Cr:YSGG laser did not increase the effectiveness of conventional acid-etching of enamel. In the present study, the microtensile values of air abrasion groups varied significantly from phosphoric acid groups $(p<0.01)$. Air abrasion is shown the lowest microtensile values, which the SEM images support (Fig. 1).

The potential drawbacks of phosphoric acid etching has made laser etching more popular. The Er:YAG laser roughs the surface of enamel effectively, including hydroxyapatite and water. Hard tissue evaporates rapidly during irradiation. The Er:YAG laser also involves water cooling, ablating surrounding tissue with minimal thermal side effects ${ }^{15}$.

Chimello-Sousa et al. ${ }^{24)}$ compared the combined Er:YAG laser system and conventional phosphoric acid with phosphoric acid alone on permanent tooth enamel and the tensile bond strength of fissure sealants after etching. They confirmed that the conventional method led to higher tensile bond strength.

Shahabi et al. ${ }^{25)}$ investigated tensile bond strength of the fissure sealants on permanent molar teeth enamel surfaces after three different etching methods: $37 \%$ phosphoric acid, Er:YAG laser (1W) and both combined. The significant differences were found between the laser-only group and the other groups. In the present study, Group 5 yielded the highest microtensile values: its SEM images showed the deepest craters, cracks, and grooves on enamel surfaces.

Moisture or saliva contamination hinders the bonding of hydrophobic resin sealants to etched enamel ${ }^{2}$. This problem is the most common reason for unsuccessful sealing ${ }^{26)}$. Other researchers have increased bond strength by adding a bonding agent layer between the etched enamel and fissure sealant ${ }^{2,17-19)}$. Feigal et al. ${ }^{19)}$, also reported a bonding agent is useful in increasing fissure sealant retention on teeth contaminated with saliva. Feigal and Donly ${ }^{14)}$ showed that applying an intermediate bonding layer reduces microleakage on saliva-contaminated enamel.

Perdigao et al. ${ }^{20)}$ compared the $\mu$ TBS values of fissure sealants after application of phosphoric acid or self-etching adhesives on permanent molar teeth. They found both groups similar.

Venker et al. ${ }^{27)}$ retrospectively investigated a selfetching primer (Prompt L-Pop) and phosphoric acid etching in a school-based fissure sealant program for a 12-month period. They demonstrated that fissure sealant retention with the use of the phosphoric acid etch was six times as likely to have retention of all the sealed tooth surfaces as those sealed with a self-etching primer.

In a randomized, controlled and split-mouth trial, Burbridge et al. ${ }^{28)}$ compared the clinical success of fissure sealants by applying a self-etching priming agent (Xeno III Dentsply, Germany) and phosphoric acid etching together with total-etching adhesive (Prime Bond NT, Dentsply, Germany) on permanent molar teeth. They found the second group more successful, concluding that self-etching adhesives could not be recommended for enamel preparation prior to fissure sealant placement.

Tunç et $a l .{ }^{21)}$ investigated the efficiency of phosphoric acid, self-etch adhesive, and etch-andrinse adhesive systems on $\mu$ TBS values of Aegis fissure sealant on bovine teeth, and found the differences between the three methods insignificant.

The bonding agent with primer and adhesive components together may enhance the initial bond to enamel and also improve adhesion between the 
adhesive and fissure sealant ${ }^{29}$. Water-based primers and adhesives could be less effective in bonding to etched and dry enamel surfaces than acetone-based adhesives ${ }^{30}$. Acetone, a volatile solvent in the adhesive system (Prime \& Bond NT), can remove all residual moisture from the etched enamel, carrying resin monomers into close adaptation with the surface. In the present study, Subgroup B of Group 5 showed the highest $\mu$ TBS mean value among all groups. In our opinion, this cleansing effect of acetone solvent may have caused the higher microtensile bond strength in the present study. These results could make great contributions for further studies. Since microtensile bond strength test is only one of numerous factors affecting dental sealants' clinical behavior, other in vitro studies should comprehensively analyze the enamel surface of lased permanent teeth. New comprehensive clinical studies are also needed to review caries prevention after different enamel preparations.

\section{CONCLUSIONS}

The following conclusions could be obtained based on results of this study:

- The Er:YAG laser may be a useful alternative to acid etching for application of fissure sealant in pediatric dentistry.

- Etch-and-rinse adhesive systems may be used with Er.YAG laser on permanent teeth.

- Amorphous calcium phosphate (ACP) containing fissure sealant, showed high microtensile bond strength values when used with $4 \mathrm{~W}$ Er:YAG laser etching.

\section{REFERENCES}

1) Hicks MJ, Flaitz CM. Epidemiology of dental caries in the pediatric and adolescent population: a review of past and current trends. J Clin Pediatr Dent 1993; 18: 43-49.

2) Simonsen RJ. Pit and fissure sealant: review of the literature. Pediatr Dent 2002; 24: 393-414.

3) Simonsen RJ. Cost effectiveness of pit and fissure sealant at 10 years. Quintessence Int 1989; 20: 75-82.

4) Buonocore MG. A simple method of increasing the adhesion of acrylic filling materials to enamel surfaces. J Dent Res 1955; 34: 849-853.

5) Foster JA, Berzins DW, Bradley TG. Bond strength of an amorphous calcium phosphate-containing orthodontic adhesive. Angle Orthod 2008; 78: 339-344.

6) Skrtic D, Antonucci JM, Eanes ED. Improved properties of amorphous calcium phosphate fillers in remineralizing resin composites. Dent Mater 1996; 12: 295-301.

7) Skrtic D, Antonucci JM, McDonough WG, Liu DW. Effect of chemical structure and composition of the resin phase on mechanical strength and vinyl conversion of amorphous calcium phosphate-based composites. J Biomed Mater Res A 2004; 68: 763-772.

8) Silva KG, Pedrini D, Delbem AC, Ferreira L, Cannon M. In situ evaluation of the remineralizing capacity of pit and fissure sealants containing amorphous calcium phosphate and/or fluoride. Acta Odontol Scand 2010; 68: 11-18.

9) Manhart J, Huth KC, Chen HY, Hickel R. Influence of the pretreatment of occlusal pits and fissures on the retention of a fissure sealant. Am J Dent 2004; 17: 12-18.
10) Andlaw RJ, Rock WP. Pit and fissure sealants. A manual of paediatric dentistry. 4th ed. London: Churchill Livingstone; 1996. p. 57-61.

11) Hatibovic-Kofman S, Wright GZ, Braverman I. Microleakage of sealants after conventional, bur, and air-abrasion preparation of pits and fissures. Pediatr Dent 1998; 20: 173176.

12) Berry EA 3rd, Ward M. Bond strength of resin composite to air-abraded enamel. Quintessence Int 1995; 26: 559-562.

13) Hibst R, Keller U. Experimental studies of the application of the Er:YAG laser on dental hard substances: I. Measurement of the ablation rate. Lasers Surg Med 1989; 9: 338-344.

14) Feigal RJ, Donly KJ. The use of pit and fissure sealants. Pediatr Dent 2006; 28: 143-150.

15) do Rego MA, de Araujo MA. Microleakage evaluation of pit and fissure sealants done with different procedures, materials, and laser after invasive technique. J Clin Pediatr Dent 1999; 24: 63-68.

16) Feigal RJ, Musherure P, Gillespie B, Levy-Polack M, Quelhas I, Hebling J. Improved sealant retention with bonding agents: a clinical study of two-bottle and single-bottle systems. J Dent Res 2000; 79: 1850-1856.

17) Hitt JC, Feigal RJ. Use of a bonding agent to reduce sealant sensitivity to moisture contamination: an in vitro study. Pediatr Dent 1992; 14: 41-46.

18) Borem LM, Feigal RJ. Reducing microleakage of sealants under salivary contamination: digital-image analysis evaluation. Quintessence Int 1994; 25: 283-289.

19) Feigal RJ, Hitt J, Splieth C. Retaining sealant on salivary contaminated enamel. J Am Dent Assoc 1993; 124: 88-97.

20) Perdigao J, Fundingsland JW, Duarte S Jr, Lopes M. Microtensile adhesion of sealants to intact enamel. Int $\mathrm{J}$ Paediatr Dent 2005; 15: 342-348.

21) Sen Tunc E, Bayrak S, Tuloglu N, Ertas E. Evaluation of microtensile bond strength of different fissure sealants to bovine enamel. Aust Dent J 2012; 57: 79-84.

22) Knobloch LA, Meyer T, Kebery RE, Johnston W. Microleakage and bond strenght of primary enamel comparing air abrasion and acid etch techniques. Pediatr Dent 2005; 27: 463-469.

23) Moslemi M, Erfanparast L, Fekrazad R, Tadayon N, Dadjo H, Shadkar MM, Khalili Z. The effect of Er,Cr:YSGG laser and air abrasion on shear bond strenght of a fissure sealant to enamel. J Am Dent Assoc 2010; 141: 157-161.

24) Chimello-Sousa DT, de Souza AE, Chinelatti MA, Pecora JD, Palma-Dibb RG, Milori Corona SA. Influence of Er:YAG laser irradiation distance on the bond strength of a restorative system to enamel. J Dent 2006; 34: 245-251.

25) Shahabi S, Bagheri HG, Ramazani K. Tensile bond strength of sealants following Er:YAG laser etching compared to acid etching in permanent teeth. Lasers Med Sci 2012; 27: 371375.

26) Asselin ME, Sitbon Y, Fortin D, Abelardo L, Rompre PH. Bond strength of a sealant to permanent enamel: evaluation of 3 application protocols. Pediatr Dent 2009; 31: 323-328.

27) Venker DJ, Kuthy RA, Qian F, Kanellis MJ. Twelve-month sealant retention in a school-based program using a selfetching primer/adhesive. J Public Health Dent 2004; 64: 191197.

28) Burbridge L, Nugent Z, Deery C. A randomized controllde trial of the effectiveness of a one-step conditioning agent in sealant placement: 6-month results. Int J Paediatr Dent 2006; 16: 424-430.

29) Hebling J, Feigal RJ. Use of one-bottle adhesive as an intermediate bonding layer to reduce sealant microleakage on saliva-contaminated enamel. Am J Dent 2000; 13: $187-$ 191.

30) Swift EJ Jr, Perdigão J, Heymann HO. Enamel bond strenghts of "one-bottle" adhesives. Pediatr Dent 1998; 20: 259-262. 